\title{
Self-ligating brackets in perspective of friction: A Review
}

\author{
Dr Barsha Thapa,' Dr Li Peng Wu² \\ 'Resident, 2Professor, Dept of Orthodontics, School of Stomatology \\ Jiamusi University, Heilongjiang Province, China
}

Correspondence: barshapaht@gmail.com

\section{INTRODUCTION}

Newton's third law of motion states that whenever a force is applied an equal and opposite force occurs in the opposite direction of applied force. Orthodontic tooth movement (OTM) being a biological phenomenon; sound knowledge of biomechanics is required. Sliding mechanics is a common approach in orthodontics to achieve tooth movement for closure and gaining of space. ${ }^{1,2}$ Sliding mechanics involves sliding of archwire along the bracket slots during the tooth movement. Bracket and archwire combination systems are basically one couple and two couple systems. ${ }^{3}$ The practitioner can apply orthodontic force systems in three principal orthogonal directions: labio-lingual (LL), mesio-distal $(M D)$, and occluso-gingival (OG). Sum-total of the forces is the vectorial sum of all these forces. Opposing to it are the resistance forces acting along the force and couple in these three principal directions and planes. To achieve better treatment outcome and patient comfort the resistance forces must be controlled by the clinician.

Resistance to sliding (RS) can be divided into three components according to Kusy and Whitley:4 (1) Friction (FR); (2) Binding (BI)- which occurs when a tooth tips or wire flexes so that there is contact between the wire and corners of the bracket; and (3) Notching (NO)- when a permanent deformation of wire occurs at the wire-bracket corner interface. Friction is the force acting in the direction parallel to that of tooth movement i.e. opposite to the direction of the applied force..$^{5}$ During OTM friction occurs because of interaction between the archwire and sides of the orthodontic bracket or a ligature.

Friction basically exists in two forms (Figure 1): (1) Static friction and (2) Dynamic/kinetic friction.6.7 OTM occurs in a series of short bursts because of the complex biologic process undergoing due to the mechanical stress and strain generated by the arch wire and bracket complex. 8.9 With the supporting evidence of biomechanics of OTM, we can mention that practically kinetic friction is irrelevant, since continuous motion of archwire does not occur in Orthodontics. Based on the review of various studies, principal factors affecting the frictional resistance are: (1) relative bracket/archwire clearance; ${ }^{10}$ (2) archwire size as related to stiffness; 11 (3) round versus rectangular archwires; ${ }^{12}$ (4) torque at the bracket/wire interface; ${ }^{13}$ (5) surface conditions of the archwires and bracket slots, ${ }^{13,14}$ (6) type and force of ligation; ${ }^{15,16}$ (7) character of relative motion at the bracket/ wire interface (tipping versus linear movement): $i^{13}$ (8) bracket and wire material; ${ }^{17}$ (9) bracket-wire angulation; (10) saliva ${ }^{18}$ and (11) bracket slot width. 4,19

Considerable amount of force is dissipated to overcome the friction. This increases the magnitude of force required to actually cause the tooth movement and achieve desired clinical result. It ultimately affects the anchorage, especially in cases with limited anchorage availability. An elastomeric ligation applies force of 50-150 gm. ${ }^{14}$ Thus knowing that major portion of resistance is because of ligation;20,21,22 self-ligating systems were introduced to decrease this phenomenon. Given the history of Russell attachment developed by $\mathrm{Dr}$ Jacob Stolzenberg in 1930's, shows self-ligating bracket concept was of early twentieth century and has got revival since then. ${ }^{23}$ Different examples of self-ligating systems are: Mobil Lock, Activa, Damon, In-Ovation, Smartclip, Clarity etc.

\section{Friction and Self ligating brackets}

For sliding mechanics during OTM, majority of force is lost due to friction. Approximately $12-60 \%$ of applied force in fixed orthodontics is lost in friction. ${ }^{24} \mathrm{~A}$ finite element analysis shows that $60-80 \%$ of the applied orthodontic force is lost during retraction of canine along a rectangular archwire by sliding mechanics. ${ }^{25}$

Iwasaki et al calculated that 31-54\% of the total frictional force generated by a premolar bracket moving along $0.019 \times 0.025$ stainless steel archwire was due to the friction of ligation

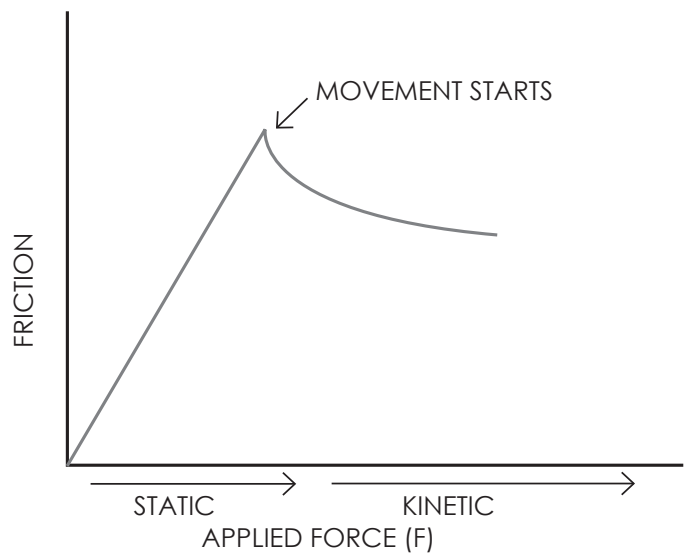

Figure 1: Friction vs. Applied force 
and the remaining $46-69 \%$ was due to elastic binding. ${ }^{21}$ So ligation is considered as an established parameter affecting the resistance to applied forces. Based on these studies selfligating brackets were introduced to decrease the amount of friction caused by ligation. It can be divided into two main types; active and passive based on their mechanism of closure. Active self-ligating brackets have a spring clip which stores the energy to press against the arch wire for rotation and torque control. While, the passive system has a slide that can be closed, which does not encroach on the slot lumen, thus does not exert any active force on the archwire. Although passive system is claimed to be superior to active system with respect to friction, ${ }^{26}$ but studies do not show results proving this assumption. ${ }^{27,28}$

According to a study by Harradine ${ }^{29}$ with conventional and selfligating brackets, the "Damon system" representing the selfligating system had better treatment outcome in treatment time, shortening the total duration to 4 months less than the conventional system. According to Scott et al, ${ }^{30}$ a randomized controlled trial showed that, with respect to clinical efficacy during tooth alignment, there was no difference between self-ligating and the conventional systems. An in vitro study by Redlich et $a^{31}$ on five different brands of "reduced friction" claiming brackets showed that there was no such "reduced friction" as claimed by the manufacturers.

A recent study conducted by Jonathan et al to understand the mechanics of bracket/archwire interaction analysis of force and couple distribution along the arch during simulated orthodontic treatment of maxillary high canine malocclusion. ${ }^{32,33}$ With the use of an orthodontic simulator the study was performed to compare the difference in the forces with passive ligation of self-ligating brackets and elastic ligation. Although some advantage of the passive self-ligation was found over the elastic ligation but the results could not confirm their use clinically. An in-vitro study showed decrease in friction with self-ligating systems. Also associated with the advantage of less friction is increased tendency of leveling losses in terms of distal rotation or the buccal root torque. ${ }^{34}$

With the use of smaller wires, self-ligating systems show less friction as compared to conventional system. ${ }^{35}$ Although selfligating systems are claimed to be superior to conventional systems, but clinical studies comparing these two systems show both being similar in terms of clinical efficacy. ${ }^{36,37}$ The

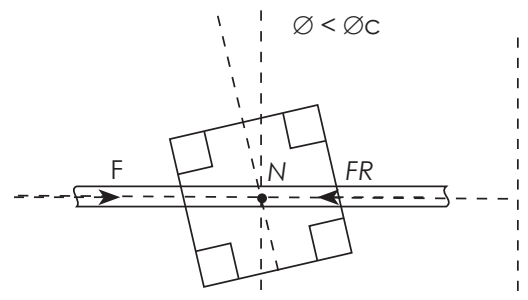

Passive Configuration

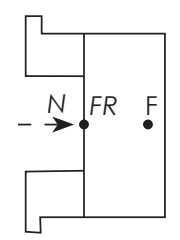

case-control study ${ }^{38}$ claiming its success is weak as per the perspective of avoiding bias and performing enough in-vivo studies. The more reliable data from randomized controlled trial does not support their superiority. ${ }^{30,39}$ Although these newer systems of course are better as per the total chair-time required and proper holding of the arch wire in bracket. ${ }^{40}$ But the claims of providing faster tooth movement and less friction is not yet confirmed with these systems. .11,42 $^{2}$

\section{Resistance to Sliding: Friction or Binding?}

In the preceding paragraphs we already discussed how "friction" has been established as the most important resistance factor, which is not true based on the scientific grounds. However self-ligating brackets are being marketed with statements like low friction, frictionless systems and faster treatment. So can we consider these systems to be superior to the conventional systems based on the claims not supported scientifically?

As mentioned earlier, binding is a phenomenon causing resistance to sliding in orthodontics. Earlier experiment on resistance to sliding were done either only considering frictional forces without knowing ligation force, ${ }^{43}$ or with known ligation force but not considering angulations. ${ }^{44}$ Based on the experiment done with combination of various cross-section archwires and brackets with different angulations, it can be established that binding has more influence than friction on the resistance forces. ${ }^{45}$

Arithmetically friction is the force that resists the movement between two objects as the product of the normal load $(N)$ and the co-efficient of friction $(\mu) .{ }^{45}$ The value $N$ is the amount of force that acts perpendicular to the surface of the object, like the ligation force $(N)$ on the bracket. The value $\mu$ is the frictional proportionality constant. The FR exists as the only component of RS, only when the arch wire and bracket are in a passive configuration. ${ }^{24}$ At this condition, the angulation $(\theta)$ between the arch wire and bracket is less than the critical angulation, $\theta c$ (the level of where the wire contacts both ends of the bracket slot). When the clearance disappears and an interference occurs $(\theta=\theta c)$, binding (BI) occurs as another component of RS. Under these conditions, two distinct normal forces exist: the $\mathrm{N}$ from ligation and the force exerted normal to the edges of the bracket slot by the arch wire (NBI). ${ }^{24}$ With the active configuration in the wire mechanics, RS will increase with $\theta$ because of Bl occurring in the appliance (Figure 2).

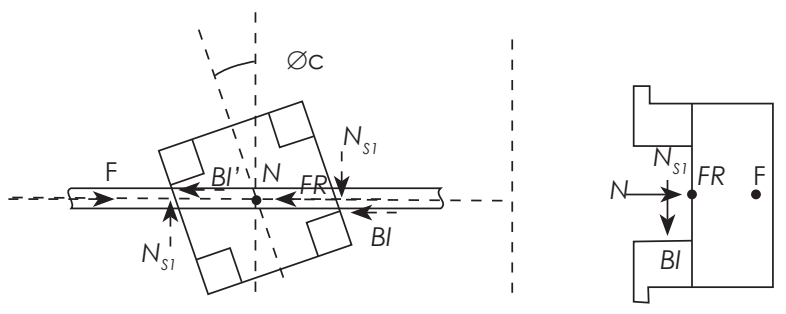

Active Configuration

Figure 2: Comparing components of resistance during passive configuration and active configuration (Figure redrawn with permission from an original research article by Articolo \& Kusy) 


\section{CONCLUSION}

Based on various studies following conclusion can be drawn:

1. Resistance is a major factor of concern during fixed orthodontic treatment.

2. Friction is a multi-factorial opposing force to the applied force, and the exact magnitude and factors affecting it are not clearly understood yet.

3. Binding phenomenon is considered more of a major opposing force affecting the tooth movement.

4. Major portion of the resistance is because of the ligation forces applied to the arch wire as been shown by different studies.
5. Although broad marketing of the self-ligating systems being done, studies show that it decreases the amount of friction due to binding but only with the thin arch wires being used along with it. And torque being a factor of concern with these systems. For which more extensive studies are required.

Though resistance to orthodontic forces are long been discussed, yet it requires more clinical studies to properly explain the phenomenon.

\section{REFERENCES}

1. Roth RK. Treatment mechanics for the straight wire appliance. In: T.M. Graber BFSE, editor. Orthodontics: Current principles and techniques. St Louis: Mosby; 1985. p. 665-716.

2. MCLaughlin RP, Bennett JC. The transition from standard edgewise to preadjusted appliance systems. J Clin Orthod. 1989;23(3):142-53.

3. Isaacson RJ, Lindaver SJ, Davidovitch M. The ground rules for arch wire design. Semin Orthod. 1995;1 (1):3-1 1.

4. Kusy RP, Whitley JQ. Influence of archwire and bracket dimensions on sliding mechanics: Derivations and determinations of the critical contact angles for binding. Eur J Orthod. 1999;21 (2):199-208.

5. Halling J. Principles of tribology. New York: MacMillan Press Ltd; 1975.

6. Bowden F, Tabor D, editors. Friction: An introduction to tribology. Garden City, New York: Anchor Press; 1973.

7. E. R, editor. Friction and wear of materials. New York: J Wiley; 1965.

8. Krishnan V, Davidovitch Ze. Cellular, molecular, and tissue-level reactions to orthodontic force. Am J Orthod Dentofac Orthop. 2006;129(4):469.e1-.e32.

9. Jack J G M Pilon, Anne M Kuijpers-Jagtman, Jaap C Maltha. Magnitude of orthodontic forces and rate of bodily tooth movement: An experimental study. Am J Orthod Dentofac Orthop. 1996;1 10(1):16-23.

10. Andreasen G, Quevedo F. Evaluation of friction forces in the $0.022 \times 0.028$ edgewise bracket in vitro. J Biomech. 1970; 3(2).

11. Frank C, Nikolai R. A comparative study of frictional resistances between orthodontic bracket and arch wire. Am J Orthod Dentofac Orthop. 1980;78(6):593-609.

12. Peterson L, Spencer R, G. A. A comparison of friction resistance for nitinol and stainless steel wire in edgewise brackets. Quintessence Int Dent Dig. 1982;13(5):563-71.

13. Kusy RP, Whitley JQ, Mayhew MJ. Surface roughness of orthodontic archwires via laser spectroscopy. Angle Orthod. 1988;58(1):33-45.

14. Sims APT, Waters ME, Birnie DJ, RJ. P. A comparison of the forces required to produce tooth movement in vitro using two self-ligating brackets and a pre-adjusted bracket employing two types of ligation. Eur J Orthod. 1993;15:377-85.

15. Kemp DW. A comparative analysis of frictional forces between self-ligating and conventional edgewide orthodontic brackets. Am $J$ Orthod Dentofac Orthop. 1993;103(2):198.

16. Max H, Ashish D, Peter R. A comparison of different ligation methods on friction. Am J Orthod Dentofac Orthop. 2006;130(5):666-70.

17. Doshi UH, Bhad-Patil WA. Static frictional force and surface roughness of various bracket and wire combinations. Am J Orthod Dentofac Orthop. 2011;139(1):74-9.

18. Kusy RP, Whitley JQ, MJ. P. Comparison of the frictional coefficients for selected archwire-bracket slot combinations in the dry and wet states. Angle Orthod. 1991;61(4):293-302.

19. Yamaguchi K, Nanda RS, Morimoto N. A study of force application, amount of retarding force, and bracket width in sliding mechanics. Am J Orthod Dentofac Orthop. 1996;109(1):50-6.

20. Schumacher H, Bourauel C, Drescher D. The effect of the ligature on the friction between bracket and arch. Journal of Orofac Orthoped. 1990; $51(2): 106-16$.

21. Iwasaki LR, Beatty MW, Randall CJ, Nickel JC. Clinical ligation forces and intraoral friction during sliding on a stainless steel archwire. Am J Orthod Dentofac Orthop. 2003;123(4):408-15.

22. Kuruvadi S, Eichmiller F, Kudlick E, Vu B. Frictional resistance: The interaction of bracket design and archwire alloy. Am J Orthod Dentofac Orthop. 1997; 1 12(3):355.

23. Rinchuse DJ, Miles PG. Self-ligating brackets: Present and future. Am J Orthod Dentofac Orthop. 2007;132(2):216-22.

24. Kusy RP, Whitley JQ. Friction between different wire-bracket configurations and materials. Semin Orthod. 1997;3(3):166-77.

25. Kojima Y, Fukui H. Numerical simulation of canine retraction by sliding mechanics. Am J Orthod Dentofacial Orthop. 2005; $127(5): 542-51$.

26. Krishnan M, Kalathil S, Abraham KM. Comparative evaluation of frictional forces in active and passive self-ligating brackets with various archwire alloys. Am J Orthod Dentofac Orthop. 2009;136(5):675-82. 
27. Pandis N, Polychronopoulou A, Eliades T. Active or passive self-ligating brackets? A randomized controlled trial of comparative efficiency in resolving maxillary anterior crowding in adolescents. Am J Orthod Dentofac Orthop. 2010;137(1):12.e1-.e6.

28. Montasser MA, El-Bialy T, Keilig L, Reimann S, Jäger A, Bouravel C. Force loss in archwire-guided tooth movement of conventional and self-ligating brackets. Eur J Orthod. 2013

29. Harradine NW. Self-ligating brackets and treatment efficiency. Clin Orthod Res. 2001;4(4):220-7

30. Scott P, DiBiase AT, Sherriff M, Cobourne MT. Alignment efficiency of damon3 self-ligating and conventional orthodontic bracket systems: A randomized clinical trial. Am J Orthod Dentofac Orthop. 2008;134(4):470.el-.e8.

31. Redlich M, Mayer Y, Harari D, Lewinstein I. In vitro study of frictional forces during sliding mechanics of "reduced-friction" brackets. Am J Orthod Dentofac Orthop. 2003;124(1):69-73.

32. Fok J, Toogood RW, Badawi H, Carey JP, Major PW. Analysis of maxillary arch force/couple systems for a simulated high canine malocclusion: Part 1. Passive ligation. Angle Orthod. 2011:81(6):953-9.

33. Fok J, Toogood RW, Badawi H, Carey JP, Major PW. Analysis of maxillary arch force/couple systems for a simulated high canine malocclusion. Angle Orthod. 2011:81(6):960-5.

34. Schumacher H, Bourauel C, Drescher D. The influence of bracket design on frictional losses in the bracket/arch wire system. J Orofac Orthop. 1999;60(5):335-47.

35. Franchi L, Baccetti T, Camporesi M, Barbato E. Forces released during sliding mechanics with passive self-ligating brackets or nonconventional elastomeric ligatures. Am J Orthod Dentofac Orthop. 2008;133(1):87-90.

36. Ong E, McCallum H, Griffin MP, Ho C. Efficiency of self-ligating vs conventionally ligated brackets during initial alignment. Am J Orthod Dentofac Orthop. 2010;138(2):138.e1-.e7.

37. Pandis N, Polychronopoulou A, Eliades T. Self-ligating vs conventional brackets in the treatment of mandibular crowding: A prospective clinical trial of treatment duration and dental effects. Am J Orthod Dentofac Orthop. 2007;132(2):208-15.

38. Eberting JJ, Straja SR, Tuncay OC. Treatment time, outcome, and patient satisfaction comparisons of damon and conventional brackets. Clin Orthod Res. 2001;4(4):228-34.

39. DiBiase AT, Nasr IH, Scott P, Cobourne MT. Duration of treatment and occlusal outcome using damon3 self-ligated and conventiona orthodontic bracket systems in extraction patients: A prospective randomized clinical trial. Am J Orthod Dentofac Orthop. 2011;139(2):e111-e6.

40. Dalessandri D, Lazzaroni E, Migliorati M, Piancino MG, Tonni I, Bonetti S. Self-ligating fully customized lingual appliance and chair-time reduction: A typodont study followed by a randomized clinical trial. Eur J Orthod. 2012.

41. Johansson K, Lundström F. Orthodontic treatment efficiency with self-ligating and conventional edgewise twin brackets. Angle Orthod. 2012;82(5):929-34

42. Read-Ward GE, Jones SP, Davies EH. A comparison of self-ligating and conventional orthodontic bracket systems. J Orthod 1997;24(4):30917.

43. 43. Tidy D, Orth D. Frictional forces in fixed appliances. Am J Orthod Dentofac Orthop. 1989:96(3):249-54

44. 44. Edwards $G$, Davies $E$, Jones $S$. The ex vivo effect of ligation technique on the static frictional resistance of stainless steel brackets and archwires. Br J Orthod. 1995;22(2):145-53.

45. 45. Articolo LC, Kusy RP. Influence of angulation on the resistance to sliding in fixed appliances. Am J Orthod Dentofac Orthop. $1999 ; 115(1): 39-51$. 